\title{
85606 - COMPARAÇÃO ENTRE DOIS PROTOCOLOS DE EXERCÍCIOS BASEADOS NO MÉTODO PÍLATES SOBRE A MOBILIDADE FUNCIONAL DE IDOSAS
}

\author{
Pôster - Gerontologia
}

Mariana dos Santos Oliveira / Oliveira, MS / PUCRS; Anelise Ineu Figueiredo / Figueiredo, AI / PUCRS; Fabiane de Oliveira Brauner / Brauner, FO / PUCRS; Lucas Athaydes Martins / Martins, LA / PUCRS; Gabriel Hoff da Silveira / Silveira, GH / PUCRS; Régis Gemerasca Mestriner / Mestriner, RG / PUCRS

Introdução: Estudos demonstram que o método Pilates (MP) é capaz de melhorar o equilíbrio postural, embora não se saiba se as variações de administração dos exercícios do método alteram a sua eficácia. Objetivo: Avaliar se a prática de exercícios derivados do MP contemporâneo em posição ortostática promove maior benefício sobre o equilíbrio de idosas quando comparada à prática de exercícios do referido método com menor volume de treinamento na posição ortostática. Método: Ensaio clínico, controlado e randomizado. Um total de 36 idosas participaram do estudo e assinaram o TCLE. As participantes foram randomizadas em grupo experimental (MP com ênfase na postura ortostática) ou grupo controle (MP com menor volume de treinamento em posição ortostática). Os protocolos de exercícios foram administrados por 12 semanas (2 sessões semanais de 50 min cada). As idosas foram avaliadas nos momentos pré e pós-intervenção. $\mathrm{O}$ desfecho principal do estudo foi o equilíbrio dinâmico, avaliado pelo Teste do Timed Up and Go (simples e em dupla tarefa cognitivo-motora), Escala de Equilíbrio de BERG e Teste do Alcance Funcional. O estudo foi aprovado pelo Comitê de Ética em Pesquisa da PUCRS (099196/2017) e registrado na plataforma ClinicalTrials.Gov (NCT03526757). Resultados: Para a análise inferencial, optou-se pela abordagem "por intenção de tratar", haja vista que foram estudados desfechos de eficácia da terapia concorrente em detrimento da intervenção convencional. A ANOVA de medidas repetidas, com ajuste para a variável de confusão "número de medicamentos contínuos em uso", revelou uma ausência de efeitos benéficos para ambos os grupos estudados. Observa-se, ainda, que os grupos, controle e intervenção, realizaram apenas 70,33\% e 72,20\% das sessões programadas, respectivamente. Apenas 16,6\% das idosas realizaram todas as 24 sessões propostas e 22,22\% completaram menos de 12 sessões. A taxa de não-retenção foi de 27,77\%. Conclusão: O MP não proporcionou benefícios no equilíbrio das idosas estudadas, o que provavelmente ocorreu dado ao excesso de faltas e consequente perda do princípio de continuidade do treinamento físico. Os resultados alertam para a necessidade de conscientizar o idoso sobre o risco de não benefício do MP em um cenário de vida real, onde as faltas são um problema frequente.

Palavras-chave: Equilíbrio postural; Técnicas de exercício e de movimento; Idoso. 